\title{
Research on application of grey system theory in construction monitoring of continuous rigid frame bridge
}

\author{
Yanjie Xue, Wei Liu* \\ Jilin University, The College of Construction Engineering, Changchun 133010, China \\ Email: weiliu16@mails.jlu.edu.cn
}

\begin{abstract}
The continuous rigid frame bridge has been widely used in practical engineering, so it has high requirement for its linear control. The Grey System Theory method is applied to the adjustment and prediction of box girder linear control in the construction control of continuous rigid frame bridge. The method is applied in the construction process of $72+133+72$ m continuous rigid frame of Manjiang Bridge. According to the monitoring data, the Grey System Theory model is used to predict, and according to the prediction results and actual construction measurement results, although the measured value is different from the theoretical value, basically, they are consistent with higher prediction accuracy, which proves the good application effect of the Grey System Theory in construction monitoring.
\end{abstract}

Keywords: Continuous Rigid Frame, Grey Theory, Construction Monitoring.

\section{OVERVIEW}

Continuous rigid frame bridge is a kind of bridge form in modern bridge. Its structure is a complex statically indeterminate system, and its ideal alignment and reasonable internal force of the bridge are not only related to design, but also depend on correct construction method.In the course of bridge construction, due to the variation of actual construction conditions, deviation of parameters of calculation model, concrete shrinkage and creep, manufacturing error, concrete quantity control, temporary construction load, hanging basket positioning and deformation, pre-stressed tendon tension, measurement error, environment disturbance, etc., the actual state value of the structure will deviate from the design value.If the system is not controlled and adjusted in time and effectively, with the increase of the construction length of the main beam's cantilever, the deviation between the linear and internal forces will gradually accumulate and eventually deviate from the design target value significantly. Therefore, it is necessary to add the construction control program in the construction process [1-4].

In Mathematics, we call a system, in which part of the information is clear and part of the information is not clear, a grey system.Professor Deng Julong, a Chinese scholar, put forward the Grey System Theory in the 1980s, which is mainly used to study the uncertainty theorieswith poor information and few data. In the process of bridge construction monitoring, there are a lot of clear information, but there are also a lot of system parameter information in incomplete, uncertain state.
In the process of bridge construction monitoring, a lot of information is clear, but also a lot of system parameter information is incomplete and uncertain. This conforms to the application conditions of the Grey System Theory, so the Grey System Theory emerges as the times requirein the construction monitoring of continuous rigid frame bridge.

\section{GREY PREDICTION CONTROL SYSTEM AND THE ESTABLISHMENT OF GREY MODEL}

At present, the main methods used in bridge construction monitoring include Kalman filtering method, least square method, artificial neural network method and Grey System Theory method.Kalman filtering is a kind of Kalman filter which applies the concept of state space to the theory of random estimation, and in construction monitoring, a discrete linear system is generally adopted [5-7].In the 1980s, it was first used in the construction monitoring of cable-stayed bridge, and achieved good results. This method has been applied to the construction monitoring of continuous rigid frame bridge only in recent years. Because of its late start, there are still some problems such as improving accuracy under the condition of less data.In the 1980s, many famous scholars in China applied the least square method to the construction monitoring of cable-stayed bridge, and achieved good achievements. Since the number of control variables is larger than the number of conditions available for adjustment, the least square method can give several adjustment schemes under the premise of minimum sum of residual error squares.In a practical project, when a control target item is defined, the period error vector can be obtained according to 
the theoretical calculation value and the actual measured value; then the parameter error to be identified can be defined, the parameter error estimation value can be calculated according to the least square estimation method to adjust the parameters; finally, a new ideal state can be obtained by forward and backward analysis of the system based on the parameters calculated by the least square estimation method.The neural network method is a kind of forward feedback-free neural network and a kind of multilayer projective network with backward transfer and error correction.In the construction monitoring of cantilever bridge, the algorithm of neural network can mainly calculate the theoretical value of main beam elevation, determine the input and output parameters, specify the initial conditions and analyze the calculation results.Since the neural network algorithm has the ability of self-adaptation and learning, the relationship of mapping will gradually conform to the objective law in the process of construction monitoring.In addition, the algorithm of artificial neural network can also be used to design parameter identification, but because artificial neural network has not established a complete theoretical system and is limited by the development of brain science, the present neural network models have obvious repairing traces, and it will lead to no solution or wrong solution to the model if the system runs for much longer time. Although the artificial neural network algorithm has been preliminarily applied in bridge construction monitoring, it needs further research and development [8-12].In bridge construction monitoring work, although a lot of information is complete and has clear input and output relations, but a lot of system parameters are incomplete and uncertain, that's, we cannot find out the explicit input and output relations of these parameters. The Grey System Theory put forward by Chinese scholar Professor Deng Julong aims at studying uncertainties with few data [13-17]. The Grey System Theory uses the data processing method to collate the seemingly irregular raw data into regular generated data, and to study the inherent relation of these data.In the 1990s, the Grey System Theory began to be applied to the construction control of long-span continuous rigid bridges and also to the construction control of cablestayed bridges [18-21].The long-span pre-stressed concrete continuous beam bridge is generally constructed in cantilever cast-in-place section by section, and the mechanical performance of the structure later is closely related to the earlier construction of the structure. The purpose of predictive control is to smooth the object output to the final set point along an ideal desired trajectory, which is called the reference trajectory, which is a function of the time (construction phase). The cast-in-situ construction of the cantilever beam of the continuous beam bridge is advanced step by step from 0 \# and 1 \# blocks. The purpose of construction control is to make the elevation of each section in each construction stage as close as possible to the reference trajectory by adjusting the elevation of vertical formwork during construction of each section, and finally make the alignment of the completed bridge conform to the design elevation as much as possible.After the construction scheme is determined, the stress and deformation of each construction stage and completed bridge structure are analyzed to determine the reference track of bridge construction. The forward loading calculation method can be used to determine the reference trajectory in bridge construction engineering.

\section{PREDICTION MODEL OF GREY SYSTEM}

In the grey system, the predictive model is $G M(1,1)$ model, with albino differential equation:

$\frac{d Z^{(1)}}{d t}+a Z^{(1)}=u$

where, $a, u$-Parameters to be identified;

$Z^{(1)}$-The accumulative generation data series of the original data $Z^{(0)}$.

The time response function obtained by solving the equation:

$Z^{(1)}(t)=\left[Z^{(1)}(1)-\frac{u}{a}\right] e^{-a(t-1)}+\frac{u}{a}$

The corresponding prediction model is obtained after the discretization of the above formula:

$Z^{(1)}(k+1)=\left[Z^{(1)}(1)-\frac{u}{a}\right] e^{-a k}+\frac{u}{a}$

For the pre-stressed concrete continuous beam bridge of cantilever cast-in-place construction, each section construction is divided into construction conditions such as hanging basket forward positioning, binding beam section reinforcing steel bar, pouring beam section concrete, stretching pre-stressed steel bar, etc.According to the ratio of the measured value and the theoretical value of the vertical displacement of the front and back beam ends, the data sequence $\mathrm{Z}$ is established, and the vertical displacement of the beam ends is predicted respectively by using the model $G M(1,1)$ in each construction working condition of the next section.

1) Prediction value of vertical displacement of beam end before and after concrete pouring $X_{1 M}(k+1)$

$X_{1 M}(k+1)=Z_{1}^{(0)}(k+1) \cdot Y_{1}(k+1)$

2) Prediction value of vertical displacement of beam end before and after tensioning pre-stressed reinforcement $X_{2 M}(k+1)$

$X_{2 M}(k+1)=Z_{2}^{(0)}(k+1) \cdot Y_{2}(k+1)$

3) Prediction value of hanging basket deformation before and after concrete pouring $X_{3 M}(k+1)$

$X_{3 M}(k+1)=Z_{3}^{(0)}(k+1) \cdot Y_{3}(k+1)$

where, $Z_{1}^{(0)}(k+1), Z_{2}^{(0)}(k+1)$ and $Z_{3}^{(0)}(k+1)$ respectively are the predicted output values of the model for the vertical displacement and the deformation of the hanging basket of the beam end before and after concrete pouring and before and after pre-stressed tendon tension in the next section; $Y_{1}(k+1), Y_{2}(k+1)$ and $Y_{3}(k+1)$ respectively are theoretical values of predicted output values of the vertical displacement and the deformation of the hanging basket of the beam end before and after concrete pouring and before and after pre-stressed tendon tension in the next section. 


\section{ENGINEERING APPLICATION}

Manjiang Bridge in Jilin Province adopts $72 \mathrm{~m}+133 \mathrm{~m}+$ $72 \mathrm{~m}$ pre-stressed concrete continuous suspended cast-in-place T-frame box beam of variable cross-section with single box and single chamber section. Thebox beam has a top width of 12.5 meters, a root width of 6.5 meters and a cantilever length of 3 meters. The top cantilever end is $20 \mathrm{~cm}$ thick and the root is $70 \mathrm{~cm}$ thick. The height of beam at the root of box girder is $8.05 \mathrm{~m}$, the height of mid-span beam is $2.7 \mathrm{~m}$, the thickness of top is $28 \mathrm{~cm}$, the thickness of rootchanges from $30 \mathrm{~cm}$ to $90 \mathrm{~cm}$ from mid-span to root, and the thickness of web is $40 \mathrm{~cm}$, $60 \mathrm{~cm}$ and $70 \mathrm{~cm}$ from mid-span to root.The height of the box girder and the thickness of the bottom plate of the box girder vary according to 1.5 parabola.According to the center line, the length of section 0 of box girder is $12.8 \mathrm{~m}$, each suspended cast-in-place $\mathrm{T}$-frame is divided into 15 sections symmetrically in longitudinal direction. The number of sections and the length of sections from root to span are $7 \times$ $3.3 \mathrm{~m}$ and $8 \times 4.5 \mathrm{~m}$ respectively, and the total length of suspended cast-in-place sections is $59.1 \mathrm{~m}$. The closure section length and the cast-in-place section length of side and middle span are $2 \mathrm{~m}$ and $4.5 \mathrm{~m}$ respectively.Two $1.9 \mathrm{~m}$ thick diaphragms are set at the root of the box girder, one $0.3 \mathrm{~m}$ thick diaphragm at the middle span and one $1.2 \mathrm{~m}$ thick diaphragm at the beam end of the side span.The Piers 1 \# and 2 \# adopt double thin-walled piers with section size of $6.5 \times$ $1.9 \mathrm{~m}$. Under the double thin-walled piers, $12.4 \times 9 \times 5 \mathrm{~m}$ caps are arranged, and $62.2 \mathrm{~m}$-diameter pile foundations are arranged under the caps.Double thin-wall piers and upper box girder are consolidated, pouring as a whole. The design load of bridge is city-A grade. Elevation and cross-section are shown in Figure 1:
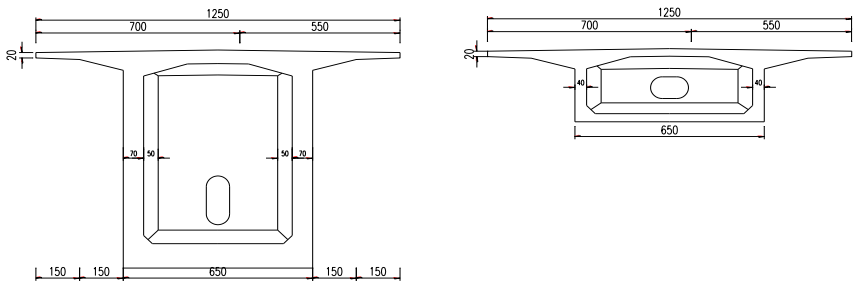

Figure 1. Cross-sectional drawing of box girder of Manjiang Bridge (Unit: $\mathrm{cm}$ )

The simulation analysis of the construction process of Manjiang Bridge indicates that the deformation of shrinkage and creep of the middle span of the main bridge for a period of three years is $37.05 \mathrm{~mm}$ (lower deflection), and the deformation caused by the $1 / 2$ vehicle and crowd load in the middle span of the main bridge is $23.68 \mathrm{~mm}$ (lower deflection).The maximum value of theoretical cumulative displacement of each section of Manjiang Bridge occurs near the closure section of side span and the closure section of middle span. The maximum theoretical value is $37.1 \mathrm{~mm}$ near the closure section of side span and $52.2 \mathrm{~mm}$ near the closure section of middle span. See Figure 2 for accumulative prethrow height value of each section node.

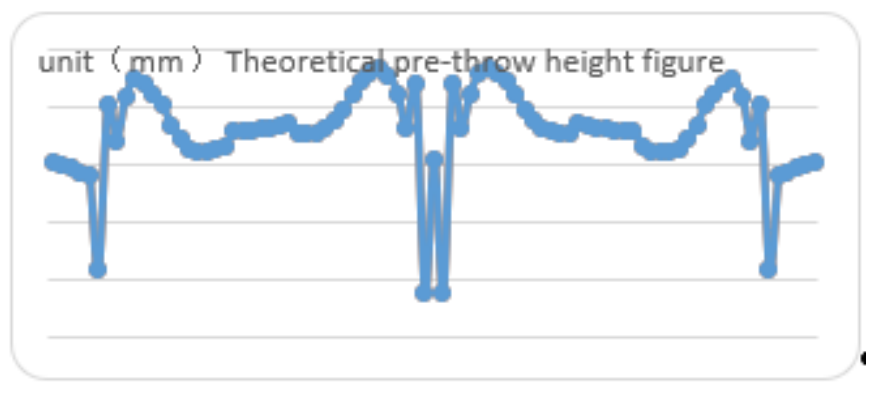

Figure 2. Theoretical pre-throw height figure of main bridge construction of luneng resort bridge in changbai mountain

The model of Manjiang Bridge is established, and the GM $(1,1)$ model is predicted by grey system theory. The values of deflection deformation after the tension in each stage is a theoretical state sequence $X=(X(1), X(2), X(3), X(4))$, and the corresponding measured values $\mathrm{Y}=(\mathrm{Y}(1), \mathrm{Y}(2), \mathrm{Y}$ (3), Y (4) are adopted. Then the error sequence $\delta=(\delta(1), \delta$ $(2), \delta(3), \delta(4))$, where, $\delta=(\mathrm{Y}(\mathrm{k}) / \mathrm{X}(\mathrm{k}), \mathrm{k}=1,2, \ldots, \mathrm{n}$, can be established according to the ratio of $\mathrm{X}$ and $\mathrm{Y}$, that's, the ratio of the predicted value of ideal state and the measured value of construction. The ratio of the theoretical deformation value to the measured deformation value for the next construction stage can be obtained through the calculation steps such as generating series, so that the elevation can be adjusted in consideration of the prediction when calculating the elevation of the vertical formwork in the next construction stage. Table 1 and Table 2 show the measured elevation values and predicted elevation values of Blocks 12 to 15 of the Manjiang Bridge. It can be seen from the table that the application of the Grey Theory in construction monitoring has high accuracy.

Table 1. Actual control of elevation of vertical formwork for pier \# 1 (unit)

\begin{tabular}{cccccccc}
\hline \multirow{2}{*}{ Location } & \multicolumn{3}{c}{ Pier 1\#small mileage } & & \multicolumn{3}{c}{ Pier 1\#big mileage } \\
\cline { 2 - 8 } & $\begin{array}{c}\text { Measured } \\
\text { elevation }\end{array}$ & $\begin{array}{c}\text { Predicted } \\
\text { elevation }\end{array}$ & Error & $\begin{array}{c}\text { Measured } \\
\text { elevation }\end{array}$ & $\begin{array}{c}\text { Predicted } \\
\text { elevation }\end{array}$ & Error \\
\hline $12 \#$ & 844.165 & 844.163 & 0.002 & 842.688 & 842.680 & 0.008 \\
\hline $13 \#$ & 844.388 & 844.386 & 0.002 & 842.773 & 842.783 & -0.01 & -0.005 \\
\hline $14 \#$ & 844.541 & 844.538 & 0.003 & 842.796 & 842.801 & 0.007 \\
\hline $15 \#$ & 844.657 & 844.651 & 0.006 & 842.788 & 842.781 & \\
\hline
\end{tabular}

Note: The error positive value in the table represents that the measured beam bottom elevation is greater than the theoretical elevation, otherwise, the error is negative; 
Table 2. Actual control of elevation of vertical formwork for pier \# 2 (unit)

\begin{tabular}{ccccccc}
\hline \multirow{2}{*}{ Location } & \multicolumn{3}{c}{ Pier 2\#small mileage } & & \multicolumn{2}{c}{ Pier 2\#big mileage } \\
\cline { 2 - 8 } & $\begin{array}{c}\text { Measured } \\
\text { elevation }\end{array}$ & $\begin{array}{c}\text { Predicted } \\
\text { elevation }\end{array}$ & Error & $\begin{array}{c}\text { Measured } \\
\text { elevation }\end{array}$ & $\begin{array}{c}\text { Predicted } \\
\text { elevation }\end{array}$ & Error \\
\hline $12 \#$ & 841.263 & 842.264 & -0.001 & 840.639 & 840.648 & -0.009 \\
\hline $13 \#$ & 842.491 & 842.488 & 0.003 & 840.696 & 840.691 & 0.005 \\
\hline $14 \#$ & 842.636 & 842.638 & -0.002 & 840.715 & 840.722 & -0.007 \\
\hline $15 \#$ & 842.759 & 842.751 & 0.008 & 840.684 & 840.681 & 0.003 \\
\hline
\end{tabular}

Note: The positive value in the table represents that the measured beam bottom elevation is greater than the theoretical elevation, otherwise, the error is negative.

\section{CONCLUSIONS}

This paper discusses some concepts of the Grey System Theory in forecasting and the method of establishing grey model. The Grey System Theory is adopted to establish the model, and the difference sequence of the theoretical deflection and the measured deflection after the tension of each section is selected as the original sequence in the construction process. The difference value between the theoretical value and the measured value in the following construction stage is predicted, and the relative error is obtained by comparing the predicted value with the measured value in the following construction stage. It is shown that the Grey System Theory can be well applied to the construction monitoring of continuous beam bridge with cantilever construction method, and the control effect of construction monitoring can be effectively strengthened. According to the monitoring data of $72+133+72 \mathrm{~m}$ continuous rigid frame bridge of Manjiang Bridge, the Grey System Theory model is used for prediction, and the application effect of Grey System Theory in construction monitoring is confirmed according to the predicted value and measuredvalue inactual construction.

\section{REFERENCES}

[1] Xiang M.S., Zhang S.B. (2002). Construction control technology of long-span prestressed concrete bridge, China Journal of Highway and Transport, pp. 38-42.

[2] Wen W.S. (2008). Continuous rigid construction control of sutong bridge auxiliary bridge, Bridge Construction, pp. 65-69.

[3] Au F.T.K., Wang J.J., Liu G.D. (2003). Control of Renforced Concrete Arch Bridges, Journal of Bridge Engineering ASCE, pp. 39-45.

[4] Xu J.L. (2000). Construction control of large span bridge, China Communications Press, pp. 124-145.

[5] Skaai F., Isoe A., Umeda A. (1991). A new methodology for control of construction accuracy in cable-stayed bridges, Shanghai: TonjiUnivesrity press, pp. 26-32.

[6] Zheng P.W., Zhong J.W., Zhu Z.X. (2009). Construction control of large span bridge, Bridge Construction, pp. 9-22.
[7] Luo F.L., Xie B.Z. (2004). Discussion on several problems of prestressed concrete continuous rigid frame bridge, China Highway, pp. 131- 133.

[8] Deng J.L. (1993). Grey control system. Huazhong university of science and technology press, pp. 50-64.

[9] $\mathrm{Hu}$ J., Liu Z.F., Xu W.S. (2010). Application of grey system theory in peace avenue overpass bridge, Construction Linear Control, pp. 28-32.

[10] Deng J.L. (1981). IntrduetionIn grey system theory, The Journal of Grey System, pp. 1-24.

[11] Tamura De P.N., Sakeshita.K. (1992). Load forecasting using gery dnyamie model, The Jounral of Grey System, pp. 76-81.

[12] Zhang X.D., Hao T.Z., Li D.C. (2006). The application of gray markov chains in continuous rigid frame bridge construction line control, Journal of Guangxi University (Natural science), pp. 24-27.

[13] Ye J.S. (2014). Principle of structural design: China Communications Press, pp. 16-33.

[14] Yao L.S. (2001). Bridge engineering. China Communications Press, pp. 211-242.

[15] Xiang H.F. (2001). Theory of structural design of higher Bridges, China Communications Press, pp. 100122.

[16] Dejus T. (2005). Evaluation of word safety control systems in construction, Civil Engineering and Management, pp. 93-98.

[17] Fleming F. (1989). Computer Analysis of Structure System, Mc Graw.Hill, pp. 513-531.

[18] Clark G. (1997). The UK Industry's Proposals for Improved Specifications and Standards for Posttensioned Concrete Bridge, In:Proc.of FIP symposium, I. ondon, pp. 31-44.

[19] Matt P. (1983). Satatus of segmental bridge construction in Europe, PCI Journal, pp. 25-47.

[20] Bakht B. (1985). Bridge ANALYSIS SIMPLIED,. New York: mcgraw-hill Book Company, pp. 127-146.

[21] Xia H.B. (2008). Fuzzy reliability prediction of bearing capacity of servo bridge based on grey markov composite model, Modern Transportation Technology, pp. $124-128$. 